\title{
College students' success in reading as a function of their preparatory school achievements
}

\author{
Bekele Birhanie Aregu \\ English Program, Faculty of Humanities, Bahir Dar University, Ethiopia.
}

Accepted 5 September, 2013

\begin{abstract}
The purpose of the study was to examine first year college students' success in reading as a function of their academic achievement in preparatory schools. To this end, data were collected from 138 year first students taking communicative English skills. Then, both descriptive and inferential statistics were employed to analyze the data. The results revealed that all of the variables were found to be correlates of students' reading performance. It was also indicated that students' college entrance English exam result was found to be a strong determinant of students' reading performance. In sum, the independent variables together accounted for $37 \%$ of the variances in students reading performance, and hence, it could be concluded that students' academic achievements in preparatory schools strongly influence college students' success in reading.
\end{abstract}

Key words: Success in reading, preparatory school achievement, reading performance.

\section{INTRODUCTION}

It is believed that in order to meet educational goals and to enhance students' success in academic exercises, studies on the determinants of academic performance (such as students' results of national examination and high school records, and other factors should be conducted, as the implications of such correlational studies are very important (Mohan, 1993; Sinn, 1985). In this regard, scholars argued that any examination that is used for the purpose of selection or prediction must be checked with some comparable forms of follow-up study. For this reason, the prediction of academic achievement at any level has been the primary concern of many researchers (Khan, 1969). In relation to this, Whitla (1972) suggested that to predict college grades, one can and should find out the multiple correlations of test scores, secondary school records, and other related variables as determinants of college grade point average.

However, Belay (1990) in his study of the predictive validity of admission criteria for teachers training institutes in Ethiopia pointed out that there is no constant evaluation of the predictive validity of tests in the
Ethiopian context. Merhatibeb (1993) also said that even ESLCE, which was the main screening mechanism for further education, was not adequately evaluated. Some researchers (for example, King and King, 1972, Tesfaye, 1983; and Adane, 1983 cited in Adnew 1999 and Merhatibeb, 1993), of course, conducted research on the relationship between ESLCE and college achievement, and they came up with a finding which shows very low relationship between ESLCE and students' college achievements. As a result, they commented that ESLCE should have been restricted to its limited role as an achievement test, and another examination (college entrance examination), which could have better predictive value, be prepared for admission in higher institutes if competent learners are to be admitted to college.

Reading does not develop suddenly, but increases gradually, depending on exposure and background. This exposure can be reading for leisure, prior knowledge, and information and communication. In this regard, Sarjant (2005) argued that in order to develop reading skills, students require prior knowledge and use of different 
strategies, existing information, resources etc. From this, one could sense that students' background knowledge and experiences play a great role in the development of students' success in reading, but the extent to which background knowledge and experiences influence students' performance in reading has not yet been clearly indicated, especially in the Ethiopian context.

Another point worth noting is that a large number of Ethiopian college students' reading performance seems to be very low regardless of the fact that students are expected to be good at reading. Actually, this problem seems to have been attributed to students' background or academic achievement in preparatory schools.

This study is, therefore, intended to investigate the effects of preparatory school achievements on first year students' reading performance. To this end, the study tries to answer the following research questions:

1. Are there correlations among grade 12 English score, grade 12 average score, college entrance examination average score, college entrance English exam score, and reading performance?

2. What are the independent and group contributions of the independent variables in projecting first year students' reading performances?

\section{METHODS}

\section{Participants}

Year one students who were taking communicative English skills in Bahir Dar University were the subjects of the study. From these subjects, 160 students were selected randomly using multistage sampling. However, 14 students who did not take all of the tests (for unknown reasons) were excluded from the sample. In addition, to minimize school background differences among students, 8 students who attended private high school were excluded from the sample to avoid exceptional cases. As a result, 138 participants who had attended government schools were involved in the study.

\section{Instruments}

Students' preparatory school academic scores and college entrance exam results were collected from students' academic document.

To measure students' reading skills, two comprehensive reading tests were prepared and sent to two experts for comments on the validity of the test items. Then the items were revised accordingly and piloted. Finally, they were administered with an interval of two days. They were then marked objectively using answer keys. The average score of the two tests for each student was taken as a measure of reading. The reliability of the two tests were calculated and found to be .86 and .88 respectively.

\section{TECHNIQUES OF DATA ANALYSIS}

To show the overview of the findings of the study such descriptive statistics as mean and standard deviations were calculated. Then, Pearson product moment correlation coefficient was used to examine the interrelationships of all the variables. Finally, multiple regression analysis was employed to examine the independent and group contributions of the predictor variables in determining students' performance in reading tests.

\section{RESULTS}

As indicated in Table 1, the mean score of grade 12 English score (59.81), and grade 12 average score (61.06) are greater than the expected mean or average score (50) for each. This seems to show that most students scored above average at preparatory school. However, the mean score of students' performance in the college entrance examination (209.46) is lower than the expected mean score (250). In connection with this, the mean score of students' college entrance English examination (45.38) is lower than the expected mean score (50). From this, one could say that most students scored below average in college entrance English exam.

Table 2 shows that the relationships of the entire predictor variables to students' reading performance are found to be significant. However, the relationships of students' reading performance to college entrance English score $(r=.50, p<.01)$ is stronger (as compared to its link with the other predictors). This seems to show that college entrance English exam score is a good predictor of reading performance (at university). However, it seems logical to examine the independent and group contributions of all the independent variables in projecting students' reading performance at university, as all of them were found statistically significant correlates even though most of them seem weak predictors.

As depicted in Table $3,37 \%$ of the variances in students' reading performance (in the freshman year) is accounted for by the combination of predictor variables $\left(\mathrm{R}=.61, \mathrm{R}^{2}=.37, \mathrm{~F}_{(4,133)}=13.86, \mathrm{p}<.05\right)$. This is likely to show the importance of the predictor variables treated for the improvement of students' reading performance. When the independent contributions of the correlates were scrutinized, college entrance English exam score $(\beta=.21$, $\mathrm{t}=2.35$, sig. $\mathrm{t}=.02$ ) was found to be a good predictor. College entrance exam average score $(\beta=.15, t=2.20$, sig. $t=.03$ ) was also found to be a significant predictor of students' reading performance. This implies that college entrance English exam score, among others, determine, to a great extent, students' reading performance. Of course, the contribution of college entrance exam average score is also significant and undeniable even though it does not seem great. But the independent contribution of the other correlates (preparatory school scores such as students' grade 12 overall average score and grade 12 English score seem statistically nonsignificant in determining first year students' reading performance.

\section{DISCUSSION}

The major purposes of the study were to investigate 
Table 1. Descriptive statistics for all subjects $(\mathrm{N}=138)$

\begin{tabular}{lcccc}
\hline Variables & Min & Max & Mean & Std. Dev. \\
\hline GRA 12 ENG & 22.0 & 86 & 59.81 & 10.77 \\
GRA 12 AV & 33.5 & 85 & 61.06 & 11.11 \\
ENT ENG & 20.5 & 68 & 45.58 & 12.68 \\
ENT AV & 121.00 & 274 & 209.64 & 29.05 \\
REA PER & 22 & 68 & 37.20 & 10.25 \\
\hline
\end{tabular}

Note. GRA12ENG=Grade 12 English score; GRA 12 AV= Grade 12 average score; ENT ENG= College entrance

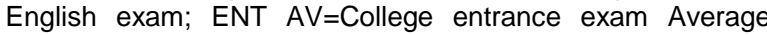
score; REA PER=Reading performance.

Table 2. Correlation Matrix (for All Variables Treated in the Study $(\mathrm{N}=138)$

\begin{tabular}{lccccc}
\hline Variable & $\mathbf{1}$ & $\mathbf{2}$ & $\mathbf{3}$ & $\mathbf{4}$ & $\mathbf{5}$ \\
\hline GRA 12 ENG & 1 & - & - & - & - \\
GRA 12 AV & $22^{*}$ & 1 & - & - & - \\
ENT ENG & $.26^{* *}$ & $46^{* *}$ & 1 & - & - \\
ENT AV & .09 & .14 & .10 & 1. & - \\
REA PER & $.22^{* *}$ & $.43^{* *}$ & $.50^{* *}$ & $.23^{* *}$ & 1 \\
\hline
\end{tabular}

${ }^{\star *} \mathrm{P}<.01$ (two tailed)

${ }^{*} \mathrm{P}<.05$ (two tailed)

college students' success in reading as a Function of their preparatory school academic achievements. Hence, the relationships of the predictor variables to the criterion variable, and the independent and group effects of the predictor variables on the dependent variable were discussed.

All the variables treated were found to be interrelated except ENTAV and the significant relationships of the variables treated could be attributed to their nature. This is because, all the variables, as has already been said, were academic scores. Another point worth mentioning, academic subjects usually relate significantly to each other (Whittla, 1981; Astin, 1975). One of the things observed in the present study is that even though college entrance average score was found to be related with reading performance even though it was not found to be a correlate of other variables. This result is in agreement with previous findings (for example, Whittla, 1981), which noted that national test scores correlate with college grade average ranging from .35 to .55 . The relationship of students' college entrance English score with reading performance $(r=.50)$ is also in the range of aforementioned research findings.

The relationship of preparatory school performance scores and entrance exam scores to reading performance were found to be significant. It seems, however, desirable to discuss, based on the outputs of the multiple regression, the independent and group effects of the predictors in the projection of first year students' reading performance at college.
College entrance English exam score was the most significant predictor of students' reading performance $(\beta=.21, t=2.35$, Sig. $t=.002)$. This seems to be indications of the need to consider students' college entrance English exam scores in the process of selecting students who join higher institutes. Obviously, this has not yet been taken into consideration. students' failure in English in general and reading skills in particular could be, therefore, attributed at least partially, to students poor background knowledge, which was reflected by especially their poor performance in the college entrance English examination. Students' college entrance exam score average was also found to be the other significant predictor of students' reading performance. From this, one can say that students who have good performance in the college entrance examinations tend to perform well in English than other students with low entrance exam scores on average. This seems to be in agreement with the findings of different scholars (for example, Whitla, 1976; Kahn, 1969), who showed that standardized tests like college entrance examinations usually help to predict students' future performance. Such results seem to be consistent with the assumption that past experiences and outcomes are likely to influence performances of the present learning (Borich and Tombari, 1995). However, the independent contributions of students' preparatory school performances (GRA 12 AV and GRA 12 ENG) to the performance of students' reading skills were found to be non-significant. Of course, this seems to be contradictory to the findings of other scholars, who showed the importance of high school scores in predicting students' college performance. Nevertheless, this contradiction might have been resulted from problems associated with teacher made tests and mode of evaluation, or from factors that are likely to jeopardize the validity and reliability of teacher made tests. Actually, this does not seem the direct concern of this study, so one can raise various questions and explore this issue.

Above all, when the group contribution of the predictors was analyzed, $41 \%$ of the variance in students' reading performance $\left(R=.61, R^{2}=.37, F_{(4,133)}=13.86, p<.05\right)$ was found to be accounted for by all the predictors that were interred into the regression equation. This result is in agreement with the assumption that when we take into account various predictors including high school performance in the prediction of students college grades, the predictability of success increases (Whittla, 1977). This could also be supported by Chauhan (1979) who says that experiences of people obviously help them perform better in their later life.

\section{CONCLUSION}

College entrance English score and college entrance exam average scores were found to be the best predictors of students' reading performance at university in the present research context. The predictor variables in 
Table 3. Multiple regression on the independent and group effects of the predictors on reading performance $(\mathrm{N}=138)$

\begin{tabular}{llcccc}
\hline Multiple $\mathrm{R}=.61$ & Variable & SEB & $\boldsymbol{\beta}$ & $\mathbf{T}$ & $\mathbf{p}$ \\
\cline { 2 - 6 } $\mathrm{R}$ square $=.37$ Standard & GRA 12 ENG & .07 & -.02 & -.32 & 74 \\
error $=7.86$ & GRA 12 AV & .09 & -.02 & -.21 & .82 \\
$\mathrm{~F}=13.86$ & ENT ENG & .06 & $.21^{*}$ & 2.35 & .02 \\
Sig. $\mathrm{F}=.000$ & ENT AV & .02 & $.15^{*}$ & 2.20 & .03 \\
\hline
\end{tabular}

${ }^{*} \mathrm{P}<.05$

combination strongly and significantly predict students' reading performance at university, but the independent contributions of preparatory school records were found to be non-significant in projecting students' reading performances at university level. Of course, this might be attributed to problems associated with the evaluation mechanisms employed at preparatory schools.

One can also say that without taking into account such considerable non-cognitive variables as self-esteem, interest, effort, etc. which could be relevant predictors of success in education, the observed substantial variation accounted for by the treated variables, which are measures of academic performance seem appreciable and informative to the bodies concerned so as to take possible remedial actions.

The study also seems to imply that the bodies concerned (for example, teachers, students, educationalist, counselors, policymakers etc.) need to design some language proficiency requirements for student admission to higher institutes. It would be also relevant to suggest further studies be conducted by taking into account such various factors as students' rural-urban background, gender, parental income level, and the like, which could contribute a lot in the projection of students' performance at university.

\section{REFERENCES}

Adnew H (1999). Predicting Achievement from ESLCE Grade, Gender and Cognitive Style: the Case of Trainees at Menelik II Mid level Health Professionals School. Bull. B. D. Teach. Col. 10(11):23-42.

Asmerom K, Lakew W, Mekonnen Y, Yosuf OA (1989). "Students Dropout from Institutions of Higher Learning in Ethiopia: Magnitude, Causes and Cures". Ethiop. J. Edu. 9(2):1-21.
Astin A (1971). "The Prediction of College Grades." The Encyclopedia of Education. 2:227-232. USA: The MacMillan Company.

Belay T (1990). An Evaluation of the Predictive Validity of Admission Criteria for Teacher Training Institute in Ethiopia. MA Thesis. Addis Ababa.

Borich GD, Tombari ML (1995). Educational Psychology: A contemporary Approach. New York: Harper Collins College Pub.

Chauhan S (1979). Adevanced Educational Psychology. New Delhi: Vikas Publishing House Ltd.

Kahn (1969). Affective Correlates of Academic Achievement. J. Educ. Psychol. 60:216-221.

King M, King J (1972). Some Correlates of University Performance in Developing countries: The Case of Ethiopia. Ethiop. J. Educ. 5(2):20.

Marshall T (1984). Educational Psychology for the Teacher in Africa. London: Ednard Arnold Publishers Ltd.

Mohan J (1993). Educational Psychology New Delhi: Wiley stem Ltd.

Merhatibeb B (1993). The Relationship between ESLCE Scores and Academic Achievement. Ethiop. J. Educ. 14:1-36.

Sarjant $R$ (2005). Developing best practice in reading tents in East Africa. 71st IFLA general Conference and Council. Oslo: 14th -18 th Aug. 2005, pp.1-10.

Sinn G (1985). Educational Psychology in a Changing World. London: George Allen and Unwin Ltd.

Whitla T (1976). Educational Evaluation: New Roles, New Means. USA: NSSE. 